\title{
Determination of material deformation rate based on artificial intelligence using surface microstructure images
}

\author{
Selim Özdem ${ }^{1}$, Ebubekir Seyyarer ${ }^{2}$ and İlhami Muharrem Orak ${ }^{3}$ \\ ${ }^{1}$ Hitit University, Alaca Avni Celik Vocational School, 19600, Alaca-Corum, Turkey \\ ${ }^{2}$ Van Yuzuncu Yil University, Gevas Vocational School, 65700, Gevas-Van, Turkey \\ ${ }^{3}$ Karabuk University, Faculty of Engineering, Computer Engineering Department, 78050 Karabuk, Turkey
}

Received: 13 June 2021, Accepted: 16 June 2021

Published online: 12 July 2021.

\begin{abstract}
Making evaluations on the ever-increasing data and thus obtaining meaningful outcome becomes more and more important in the digital age. Thanks to the recent advances in artificial intelligence technologies, processing this data and making predictions is very popular. Within the scope of this study, S235 JR steel, which is used in many areas such as bridges, railways, industrial buildings, vehicle manufacturing and oil-gas exploration stations, has been deformed at different rates in the laboratory environment. Microstructure images of the deformed materials were obtained with the help of a microscope after some metallographic processes. As a result of the study, it is aimed to contribute to the literature by creating a data set containing microstructure images of S235 JR steel, which has been deformed at different rates. In addition, Convolutional Neural Network (CNN) and Multilayer Artificial Neural Network (ANN) models, which are among the deep learning methods of artificial intelligence technology, were used to classify the deformation rates. In order to minimize the error in both deep learning models, Adam Optimization Algorithm has been preferred. The results obtained with the Adam Optimization Algorithm in CNN and Multilayer ANN models were compared and the highest success in the classification process was obtained in the CNN model.
\end{abstract}

Keywords: Artificial Intelligence, CNN, Multilayer YSA, S235 JR structural steel.

\section{Introduction}

As the amount of data and the speed of accessing data increase day by day, the need for the necessary hardware to process this data is also increasing. It is seen that deep learning studies could not progress at the desired speed until 2000 due to the need for powerful hardware used in data processing processes [1]. With the increase in the working speed of computers and the use of graphics processor units in calculations, great developments are realized. In addition, highly capable architectures such as LeNet-5, AlexNet, Google Net/Inception, VGG-16, ResNet have emerged in data processing, classification and analysis [2-6]. The meaningful data production obtained with these developments makes a significant contribution to many sectors such as health, service and defense industry [7-10]. Artificial intelligence can also be defined as the ability of a computer or computer-assisted machine to make sense of large information or perform tasks related to higher logical processes, such as finding solutions, understanding, generalizing, and learning from past experiences [11], which are usually human characteristics. In short, Artificial Intelligence is automatic systems that can produce algorithms.

In recent years, machine learning techniques, one of the artificial intelligence technologies, are frequently used in the field of materials science [12]. There is a direct relationship between material life and the rate of deformation of the 
Table 1: Dataset categories

\begin{tabular}{|l|l|l|l|}
\hline Category Nu. & Category Name & Image Count & $\begin{array}{l}\text { Images Size } \\
(\text { Piksel - px })\end{array}$ \\
\hline 1 & Raw sample & 2000 & $128 \times 128 \mathrm{px}$ \\
\hline 2 & $7 \mathrm{~mm}$ extended sample & 2000 & $128 \times 128 \mathrm{px}$ \\
\hline 3 & $14 \mathrm{~mm}$ extended sample & 2000 & $128 \times 128 \mathrm{px}$ \\
\hline 4 & $21 \mathrm{~mm}$ extended sample & 2000 & $128 \times 128 \mathrm{px}$ \\
\hline 5 & The broken sample & 2000 & $128 \times 128 \mathrm{px}$ \\
\hline \multicolumn{2}{|l|}{} & 10000 & \\
\hline
\end{tabular}

material, and some deformations are irreversible $[13,14]$. Therefore, deformation analysis is a very critical issue for materials. Deteriorations in the material structure can be understood by looking at their microstructure [15, 16]. Techniques such as computer vision, image processing and data analysis can be used for deformation analysis on materials. In this context, machine learning methods under the title of artificial intelligence, which is one of the main development points of Computer Engineering, are used in many studies today as in the recent past. Figure 1 shows schematically the initiation and propagation of cracks in the microstructure of a material.

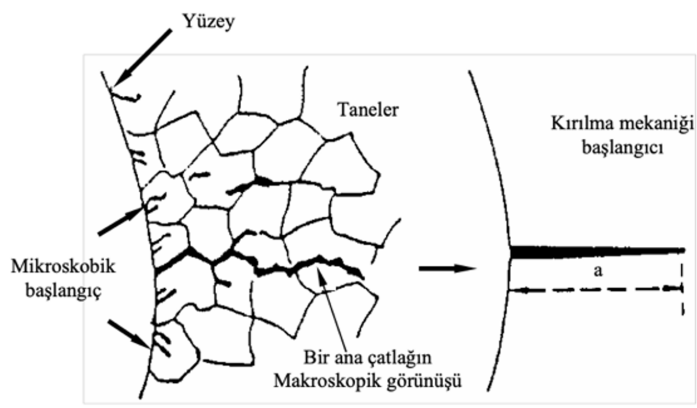

Fig. 1: Initiation and propagation of crack in the material $[15,16]$

In this study, after taking samples from S235 JR structural steel, they are deformed at different rates. As a result of this process, a data set consisting of microstructure images is created and it is aimed to determine the deformation rates with Multilayer ANN and CNN models. In addition, the most widely used Adam optimization algorithm was preferred to reduce the error rate. Of the study In section 2 the creation of the data set, in section 3 the Multilayer ANN model, in section 4 the CNN model, in section 5 the experimantal study and in section 6 results.

\section{Data set}

It is stated in the literature that S235 JR steel elongates by $25 \%$ [17]. In this study, samples taken from this material, which elongated by one fourth of its length, were subjected to tensile tests in the metallurgical materials laboratory and deformed. The deformation process was carried out in five categories shown in Table 1.

After the tensile test, the samples were passed through metallographic stages (cutting, coarse-fine sanding, polishing, etching) in order to visualize the surface microstructure of the samples under the microscope. Then, the images obtained with the microscope were categorized according to their deformation rates, and a new data set was brought to the literature. The classified images are separated as $70 \%$ training and $30 \%$ test data. The data samples obtained in this study 


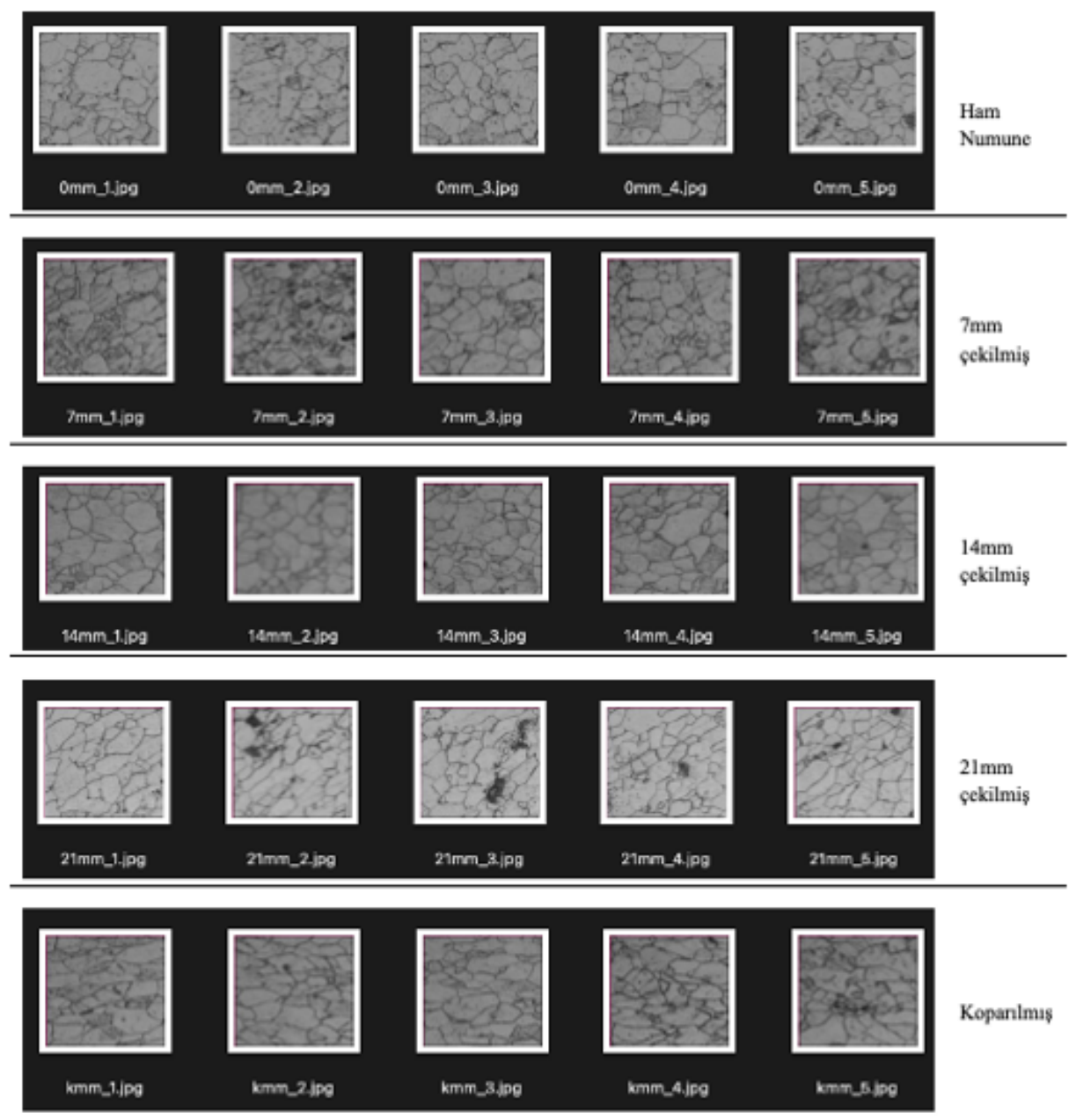

Fig. 2: The resulting data set from the tensile tests

are shown in Figure 2 in categories.

Steel used as a structural material has become a prominent material in the construction sector, especially after the 1999 Marmara earthquake [18]. Structural steels are used in many sectors [19]. Over time, structural materials under load undergo deformation. Material deformations are examined in two ways, by physically destructive and non-destructive testing. In the destructive examination, parts are taken from the material and analyzed by experts in the field of metallurgy-materials engineering and chemists in the laboratory environment. Non-destructive testing, on the other hand, is carried out by obtaining the microstructure of the material by various methods without removing any parts [20-22]. In this study, S235 JR structural steel is chosen due to its features such as widespread use, lightness and flexibility, and microstructure images were obtained by destructive testing method [23].

\section{Multilayer artificial neural networks}

Multilayer ANN is a model that is processed under the concept of deep learning [24]. ANN generates information/(outputs) in a set of operations based on different inputs and neurons [25]. An ANN consists of many units called neurons. ANN basically consists of 3 layers: input layer, hidden layer and output layer. In the input layer, vectorial 
values are given to the network as input information [11]. Each data in the input layer is multiplied by random weight values and transmitted to the hidden layer. The result obtained is processed by an activation function in the hidden layer and sent to the output layer [26]. The activation function is a function that decides whether the neuron in the artificial neural network will be active or not. There are various activation functions such as sigmoid, tanh, relu, leaky relu, softmax, which will be decided according to the problem in question [27]. Because the computational load of the Relu activation function is less than the sigmoid and hyperbolic tangent functions, it is more preferred in multilayer networks [28].

\section{Convolutional neural network}

Convolutional neural network, which is one of the popular deep learning algorithms, is generally used in areas such as image processing, natural language processing and is very successful in image classification processes [29]. Yann LeCun announced the first CNN model called LeNet with his articles published in 1995 [30]. CNN processes the image with various layers. These layers are;

-Convolutional Layer - Used to detect features.

-Non-Linearity Layer - Used to introduce nonlinearity to the system.

-Pooling Layer - Reduces the number of weights and controls fit.

-Flattening Layer - Prepares data for classical neural network.

-Fully-Connected Layer - It is the standard neural network used in classification.

\section{Experimental study}

In the study, the deformation rate is determined in the data set we obtained by using the Multilayer ANN and CNN models described above. The results obtained in different iterations are compared. The application is coded in the Python programming language.

\subsection{Application of multilayer ANN model on dataset}

The number of inputs is kept high in the neural network used in this study. The purpose of this is to increase the classification success. In the application, there are two middleware layers with the first layer having 64 nodes and the second middle layer having 32 nodes. Application steps are shown below. The created multilayer ANN model is shown in Figure 3.

(1) Giving the image as input to the system.

(2) The process of turning the inputs to gray level.

(3) Resize input dimensions to $64 \times 64$ pixels.

(4) Process of separating data for five categories.

-\%30 Test data

-\%70 Training data

(5) Modeling the neural network by giving the training data to the network

-Using activation functions (Relu, Softmax).

-Using the Adam optimization algorithm

(6) Application of test data to the model.

(7) Analysis of results. 


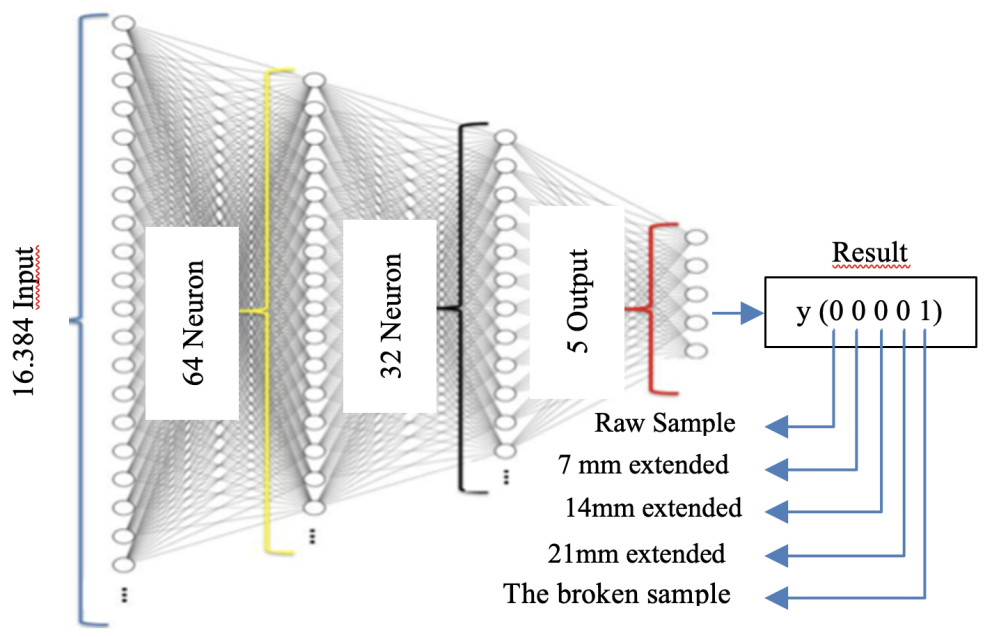

Fig. 3: Multilayer ANN model

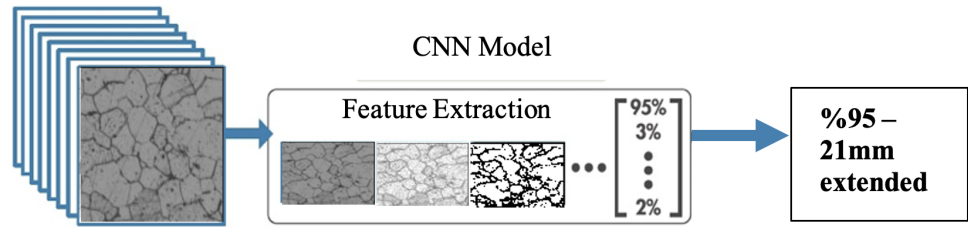

Fig. 4: CNN model

\subsection{Implementation of the CNN model on the data Set}

In this study, Adam algorithm, one of the gradient descent optimization algorithms, was applied to our data set in different iterations, and the results were compared. The CNN model used in the application is shown in Figure 4 and the structure of the CNN layers is shown in Table 2.

In the data set, there are 7000 images in the training set and 3000 images in the test set, equally from each category. Dimensions shown as $128 \times 128$ show the pixel value of the picture.

\section{Results}

The values shown in Table 3 were obtained by testing multi-layer ANN and CNN models from deep learning models on the original data set created for material deformation rate classification. More successful results were obtained with the CNN model in the models designed using the Adam algorithm, which is the most popular optimization algorithm.

When the results of the study are evaluated, it is concluded that although the images in the data set are close to each other, high success rates are achieved with very low iteration numbers in the image classification processes of the CNN model. 
Table 2: CNN model feature

\begin{tabular}{|l|l|}
\hline Layers & Layers Feature \\
\hline Convolutional & Conv2D \\
\hline Activation & Relu \\
\hline Dropout & 0.2 \\
\hline BatchNormalization & \\
\hline Convolutional & Conv2D \\
\hline Activation & MaxPooling2D \\
\hline Pooling & 0.2 \\
\hline Dropout & \\
\hline BatchNormalization & \\
\hline Convolutional & Conv2D \\
\hline Activation & Relu \\
\hline Pooling & MaxPooling2D \\
\hline Dropout & 0.2 \\
\hline BatchNormalization & \\
\hline & \\
\hline Convolutional & Conv2D \\
\hline Activation & Relu \\
\hline Dropout & 0.2 \\
\hline BatchNormalization & \\
\hline Flatten & \\
\hline Dropout & 0.2 \\
\hline & \\
\hline Dense & 256 \\
\hline Activation & Relu \\
\hline Dropout & 0.2 \\
\hline BatchNormalization & \\
\hline Dense & 128 \\
\hline Activation & Relu \\
\hline Dropout & 0.2 \\
\hline BatchNormalization & \\
\hline Dense & \\
\hline Activation & Softmax \\
\hline
\end{tabular}

Table 3: Comparison of Application Results of Multilayer ANN and CNN Models on Data Set

\begin{tabular}{|l|l|l|l|}
\hline $\begin{array}{l}\text { Deep Learning } \\
\text { Model }\end{array}$ & Optimization Algorithm & Iteration Count & Test Classification Success Rate \\
\hline \multirow{3}{*}{ Multilayer ANN } & \multirow{2}{*}{ Adam } & 300 & 0.6517 \\
\cline { 3 - 4 } & & 600 & 0.6895 \\
\cline { 3 - 4 } & \multirow{3}{*}{ CNN } & 1000 & 0.5196 \\
\cline { 3 - 4 } & Adam & 15 & 0,7820 \\
\cline { 3 - 4 } & & 20 & 0,7932 \\
\hline
\end{tabular}

In future studies, the success rates of other optimization algorithms in multilayer ANN and CNN models will be examined and compared with the Adam optimization algorithm used in this study. In addition, the development of a hybrid optimization algorithm is considered.

\section{Competing interests}

The authors declare that they have no competing interests. 


\section{Authors' contributions}

All authors have contributed to all parts of the article. All authors read and approved the final manuscript.

\section{References}

[1] Schmidhuber, J., Deep learning in neural networks: An overview. Neural networks, 2015. 61: p. 85-117.

[2] LeCun, Y., et al., Gradient-based learning applied to document recognition. Proceedings of the IEEE, 1998. 86(11): p. $2278-2324$.

[3] Krizhevsky, A., I. Sutskever, and G.E. Hinton. Imagenet classification with deep convolutional neural networks. in Advances in neural information processing systems. 2012.

[4] Szegedy, C., et al. Going deeper with convolutions. in Proceedings of the IEEE conference on computer vision and pattern recognition. 2015.

[5] Simonyan, K. and A. Zisserman, Very deep convolutional networks for large-scale image recognition. arXiv preprint arXiv:1409.1556, 2014.

[6] He, K., et al. Deep residual learning for image recognition. in Proceedings of the IEEE conference on computer vision and pattern recognition. 2016.

[7] Yu, X., et al., Deep learning in remote sensing scene classification: a data augmentation enhanced convolutional neural network framework. GIScience \& Remote Sensing, 2017. 54(5): p. 741-758.

[8] Delen, D., G. Walker, and A. Kadam, Predicting breast cancer survivability: a comparison of three data mining methods. Artificial intelligence in medicine, 2005. 34(2): p. 113-127.

[9] Walek, B., O. Hosek, and R. Farana. Proposal of expert system for hotel booking system. in 2016 17th International Carpathian Control Conference (ICCC). 2016. IEEE.

[10] Ayalew, A., A review on object detection from Unmanned Aerial Vehicle using CNN. 2019.

[11] Nabiyev, V.V., Yapay Zeka, ed. 598-599. 2016, Ankara: Seckin Yayincilik.

[12] Bulgarevich, D.S., et al., Pattern recognition with machine learning on optical microscopy images of typical metallurgical microstructures. Scientific Reports, 2018. 8(1): p. 2078.

[13] Kachanov, L., Introduction to continuum damage mechanics. Vol. 10. 1986: Springer Science \& Business Media.

[14] Chaboche, J.-L., Continuum damage mechanics: Part II-Damage growth, crack initiation, and crack growth. 1988.

[15] Chaboche, J.-L., Continuum damage mechanics: Part I-General concepts. 1988.

[16] Chaboche, J.-L., Continuous damage mechanics-a tool to describe phenomena before crack initiation. Nuclear Engineering and Design, 1981. 64(2): p. 233-247.

[17] Yürük, A., B. Bozkurt, and N. Kahraman, S235JR karbon celigi ile AISI 430 ferritik paslanmaz celigin MIG kaynak y ̃̃đntemi ile kaynak edilebilirliginin incelenmesi. Sakarya University Journal of Science, 2017. 21(2): p. 90-97.

[18] Şık, A., MIG/MAG kaynak yöntemi ile birleştirilen çelik malzemelerde ilave tel türleri ve koruyucu gaz karışımlarının egmeli yorulma ömürlerine etkilerinin araştırılması. Gazi Üniversitesi Mühendislik Mimarlık Fakültesi Dergisi, 2007. 22(4): p. $769-777$.

[19] Aydin, S., Yapi Celiginin (St52-3) Mig/Mag Kaynaginda Gaz Karisimlarinin Cekme Dayanimi Ozelliklerine Etkisi. Trakya Univ J Sci, 2006. 7(1): p. 9-15.

[20] Ege, Y., Ferromanyetik malzemeler uzerindeki catlaklarin manyetik yontemle belirlenmesi. 1998, Balikesir Universitesi Fen Bilimleri Enstitusu.

[21] Kaya, Y. and N. Kahraman, Farkli ozellikteki malzemelerin tozalti ark kaynak yontemi ile birlestirilmesi ve birlestirmelerin tahribatli ve tahribatsiz muayenesi. Sakarya Universitesi Fen Bilimleri Enstitusu Dergisi, 2013. 17(1): p. 85-96.

[22] Ozkan, E., Kaynak sonrasi S355J2N yapi celiginde olusan gerilmeleri gidermek icin uygulanan isil islemin etkilerinin tahribatlitahribatsiz muayene yontemleriyle belirlenmesi. 2019, Namik Kemal Universitesi.

[23] Askon. S235JR ve S355J2 + N. 2021; Available from: https://www.askondemir.com/sac-grubu/siyah-sac.

[24] Aizenberg, I.N., N.N. Aizenberg, and J. Vandewalle, Multiple-Valued threshold logic and multi-valued neurons, in Multi-Valued and Universal Binary Neurons. 2000, Springer. p. 25-80.

[25] Lin, T.-H., A cross model study of corporate financial distress prediction in Taiwan: Multiple discriminant analysis, logit, probit and neural networks models. Neurocomputing, 2009. 72(16-18): p. 3507-3516. 
117 Z16 S. Özdem, E. Seyyarer and İ. M. Orak: Determination of material deformation rate based on artificial ...

[26] Etheridge, H.L. and R.S. Sriram, A comparison of the relative costs of financial distress models: artificial neural networks, logit and multivariate discriminant analysis. Intelligent Systems in Accounting, Finance \& Management, 1997. 6(3): p. $235-248$.

[27] Hwang, J.G. and A.A. Ding, Prediction intervals for artificial neural networks. Journal of the American Statistical Association, 1997. 92(438): p. 748-757.

[28] Mishkin, D. and J. Matas, All you need is a good init. arXiv preprint arXiv:1511.06422, 2015.

[29] Li, Y., et al., Deep learning for remote sensing image classification: A survey. Wiley Interdisciplinary Reviews: Data Mining and Knowledge Discovery, 2018. 8(6): p. e1264.

[30] LeCun, Y. and Y. Bengio, Convolutional networks for images, speech, and time series. The handbook of brain theory and neural networks, 1995. 3361(10): p. 1995. 